IMAGE study, 7 hospital deaths occurred in 434 placebotreated patients $(1.6 \%)$. This is similar to the $1.8 \%$ hospital mortality reported for non-aprotinin treated patients by Weightman and Newman. However, aprotinin-treated patients in the IMAGE study had a substantially lower hospital mortality than those patients treated with a comparable dose $(\geq 4,000,000 \mathrm{KIU})$ in Weightman and Newman's letter: $1.4 \%$ compared with $11.5 \%$.

Weightman and Newman report that of 754 patients receiving aprotinin, $93 \%$ received less than 4,000,000 KIU of aprotinin (see their Table I). Their reporting of the total dose makes unclear the administration regimen (ie, pump only, half dose, or full dose, as in the IMAGE study) and timing (from the beginning of the operation, as recommended, or, perhaps, after loss of hemostasis). Furthermore, and with the exception of pump-only administration, aprotinin is typically administered as a constant infusion per hour. In the simplest scenario (no pump or loading dose), any differences in the amount of aprotinin administered would result wholly from the length of the operation.

The variables that separated European from US patients in the IMAGE study were primarily related to adverse angiographic characteristics of the recipient vessels in addition to female sex, older age, prior aspirin use, and abnormal left ventricular ejection fraction. The only predictor variables in the IMAGE study for which there are data in Weightman and Newman's patient population (Anesth Analg 1999;88:286-91) are age, sex, and aspirin use. Their patients were older than those in the IMAGE study (63.8 years compared with 61.6 years at US sites and 62.0 years at Danish and Israeli sites), had a higher proportion of women (20.5\% compared with $9.4 \%$ at US sites and $14.3 \%$ at Danish and Israeli sites), and a higher proportion of aspirin users (58.8\% compared with $42.8 \%$ at US sites and $26.1 \%$ at Danish and Israeli sites). In the IMAGE study, aspirin use was associated with a lower risk of graft occlusion, whereas the other 2 variables, sex and age, were consistent with patients having a higher risk for vein graft occlusion. Comparative data on Weightman and Newman's patient characteristics are too limited to determine whether responses are more similar to those observed in our European or US patient populations. It is also unclear whether Weightman and Newman's data are prospective or retrospective.

These differences suggest that patients in Weightman and Newman's population-and particularly those receiving aprotinin - had a more adverse patient profile than either US or European patients in the IMAGE study or there were other technical differences in the surgical procedures. Thus inferences should not be made from a nonrandomized study, particularly one with apparent treatment biases.

Edwin L. Alderman, MD For the IMAGE Investigators Division of Cardiovascular Medicine Stanford University School of Medicine Falk Cardiovascular Research Center CV-261, 300 Pasteur Dr Stanford CA 94305-5406 12/8/101196

\section{Abciximab (ReoPro) removal with a hemoconcen- trator during cardiopulmonary bypass}

\section{To the Editor:}

The problem of performing emergency cardiac surgery on patients who have been recently treated with abciximab (ReoPro, Eli Lilly and Company, Indianapolis, Ind) as addressed by Poullis and associates ${ }^{1}$ is indeed of considerable interest to surgeons. The in vitro experiment they described, however, may have limited applicability to the clinical situation of operating on a patient who has been recently treated with abciximab. In their method, abciximab was added to a solution of saline and then subjected to hemoconcentration during circulation in an in vitro cardiopulmonary bypass circuit. However, platelets were not included in the test solution. This protocol is quite different from the situation of a patient who has been recently treated with abciximab and who does have platelets.

Poullis and associates state that the purpose of hemofiltration is to remove free abciximab so that subsequently administered donor platelets will have the role of providing hemostasis rather than "primarily absorbing free antibody." This hypothesis, however, is not consistent with the pharmacodynamic profile of abciximab.

When abciximab is administered, the drug rapidly binds to the platelet glycoprotein IIb/IIIa receptors and results in severe inhibition of platelet aggregation and prolongation of the bleeding time. ${ }^{2,3}$ The binding of abciximab to the platelets is noncompetitive and the dissociation rate from platelets is slow. Excess non-bound abciximab is rapidly cleared, and within 30 minutes of abciximab administration less than $4 \%$ of the administered dose is present within the serum as free antibody. ${ }^{4}$ Thus essentially no abciximab is available for removal by hemofiltration. Likewise, when donor platelets are transfused, no free abciximab is present to be "absorbed." When platelets are transfused there is, however, redistribution of abciximab from native (bound) platelet receptors to transfused (unbound) platelet receptors, resulting in an overall reduction in the percentage of bound receptors. When this overall percentage of blocked receptors falls below approximately $80 \%$, the bleeding time and hemostasis return toward normal. This is the rationale for transfusing platelets to reverse the effect of abciximab. ${ }^{3,4}$

Potential methods to reduce the bleeding diathesis in patients requiring surgery while under the effect of abciximab are welcome to surgeons who have to deal with this problem. At present, however, platelet administration to dilute the abciximab blockade of the platelet glycoprotein IIb/IIIa receptors would appear to be the antidote of choice. My colleagues and $\mathrm{I}^{5}$ recently reported experience with 12 patients who required emergency coronary artery bypass grafting shortly after abciximab treatment. The routine transfusion of 1 apheresis platelet unit (volume equal to 6 random donor platelets but acquired from a single donor) after reversal of heparin effect by protamine, with addition- 
al blood product transfusions given as required, was clinically successful.

\section{John H. Lemmer, Jr, MD \\ Legacy Good Samaritan Hospital \\ NW Surgical Associates \\ 2222 NW Lovejoy, No. 315 \\ Portland, OR 97210}

\section{REFERENCES}

1. Poullis M, Manning R, Haskard D, Taylor K. ReoPro removal during cardiopulmonary bypass using a hemoconcentrator. J Thorac Cardiovasc Surg 1999;117:1032-4.

2. Tcheng JE, Ellis SG, George BS, et al. Pharmacodynamics of chimeric glycoprotein IIb/IIIa integrin antiplatelet antibody Fab 7E3 in high-risk coronary angioplasty. Circulation 1994;90: 1757-64.

3. Mascelli MA, Lance ET, Damaraju L, Wagner CL, Weisman HF, Jordan RE. Pharmacodynamic profile of short-term abciximab treatment demonstrates prolonged platelet inhibition with gradual recovery from GP IIb/IIIa receptor blockade. Circulation 1998; 97:1680-8.

4. Coller BS. GP IIb/IIIa antagonists: pathophysiologic and therapeutic insights from studies of c7E3 Fab. Thromb Haemost 1997;78:730-5.

5. Lemmer JH Jr, Metzdorff MT, Krause AH, Martin MA, Okies JE, Hill JG. Emergency coronary artery surgery in abciximab-treated patients. Ann Thorac Surg. In press.

$12 / 8 / 101562$

\section{Reply to the Editor:}

Lemmer raises a number of interesting points with regard to the removal of abciximab (ReoPro) during cardiopulmonary bypass with the use of a hemoconcentrator. ${ }^{1}$

First, as correctly pointed out, the experiments were initially carried out with normal saline solution, as a proof of principle. However, as stated in the article, the experiments were repeated with the use of packed red cells to maintain clinical relevance. As the free abciximab is biologically active (Eli Lilly and Company data sheet), then our protocol, even though simplified, was clinically relevant.

Second, with regard to analyzing native platelet function, platelet dysfunction after cardiopulmonary bypass occurs for a myriad of known and unknown preoperative and perioperative reasons, making the evaluation of an intervention difficult. The aim of this study was to demonstrate a technique to reduce the inhibition of transfused platelets that occurs as a result of abciximab inactivation. This should result in a reduction of postoperative platelet transfusion requirements and transfusion-related complications, for example, adult respiratory distress syndrome. We make no claims to reversal of the effect of abciximab on native platelets. However, by implication from our results and the fact that abciximab binding is known to be a reversible process, hemofiltration will result in at least a partial reversal of the effect of abciximab on native platelets.

Third, Lemmer states that the dissociation of abciximab from platelets is slow, but he then states that abciximab redistribution from native platelets to transfused platelets occurs immediately after their administration, a kinetics contradiction. Either a platelet-to-platelet interaction occurs (microaggregation, which is known not to be the case) or free abciximab is involved. It is this free abciximab that Lemmer quite rightly implicates in causing transfused platelet dysfunction, which we demonstrated can be reversed.

Care should be taken with regard to interpretation of percentage glycoprotein IIb/IIIa receptor binding as evaluated in reference 3 provided by Lemmer, since no platelet function tests were performed, just fluorescence-activated cell sorter analysis, which does not necessarily correlate with physiologic function. The prior administration of aspirin or clopidogrel, for example, will result in an uninterpretable result in this situation.

In addition to abciximab (ReoPro), tirofiban (Aggrastat) and eptifibatide (Integrilin) are also specific glycoprotein IIb/IIIa inhibitors. The possible reversal of bleeding caused by glycoprotein IIb/IIIa inhibition therapy via hemofiltration is now alluded to by the drug information data sheets produced by Merck, which manufactures Aggrastat, and COR Therapeutics, Inc, and Key Pharmaceuticals, Inc, which manufacture Integrilin.

Unfortunately, we do not have access to the publication of Lemmer's group (in press). It would be interesting to note what degree of preoperative platelet inhibition was present in their patients, since it is widely known that abciximab has a variable clinical effect. Conventional platelet function tests are impractical in an emergency situation. However, we have recently demonstrated a quick, simple test of platelet inhibition caused by abciximab, via the technique of whole blood microaggregation, which involved the use of a standard laboratory Coulter counter (Coulter Electronics, Inc, Hialeah, Fla). ${ }^{3}$ This should aid in assessing preoperative platelet inhibition, thus making it possible to rank patients by their susceptibility to bleeding, so that accurate evaluation of any antibleeding strategy can be ascertained.

Michael Poullis, MD

Department of Cardiothoracic Surgery Hammersmith Hospital

Du Cane Rd

East Acton

National Heart and Lung Institute Imperial College of Science London W12 ONN, United Kingdom

\section{REFERENCES}

1. Poullis M, Manning R, Haskard D, Taylor K. ReoPro removal during cardiopulmonary bypass using a hemoconcentrator. J Thorac Cardiovasc Surg 1999;117:1032-4.

2. Mascelli MA, Lance ET, Damaraju L, Wagner CL, Weisman HF, Jordan RE. Pharmacodynamic profile of short-term abciximab treatment demonstrates prolonged platelet inhibition with gradual recovery from GP IIb/IIIa receptor blockade. Circulation 1998;97:1680-8.

3. Poullis M. A quick simple method of determining platelet aggregability following glycoprotein IIb/IIIa receptor inhibitor administration. Cardiology 1999;91:156-60.

$12 / 8 / 101561$ 